\title{
Effect of Thrombin Concentration on the Adhesion Strength and Clinical Application of Fibrin Glue-Soaked Sponge
}

\author{
Francia CAmpos, ${ }^{1}$ Shingo FUjIO, ${ }^{1}$ Sei SugatA,${ }^{1}$ Hiroshi TOKIMURA, ${ }^{1}$ \\ Ryosuke HANAYA, ${ }^{1}$ Manoj BOHARA, ${ }^{1}$ and Kazunori ARITA ${ }^{1}$ \\ ${ }^{1}$ Department of Neurosurgery, Graduate School of Medical and Dental Sciences, \\ Kagoshima University, Kagoshima, Kagoshima
}

\begin{abstract}
Fibrin glue-soaked gelatin sponge (FGGS) has been used for tissue sealing in neurosurgical practice, but too rapid clotting of fibrin glue occasionally prevents good fixation of FGGS. Dilution of thrombin may provide adequate manipulation time between mixing fibrinogen and thrombin on gelatin sponge and application into the tissue defects. The present study characterized the effect of thrombin dilution on the adhesion strength of FGGS and retrospectively assessed the clinical usage of the dilution for filling dead space or sealing arachnoid defect in 255 cases who underwent transsphenoidal surgery for the last 66 months. FGGS was prepared using three different concentrations of thrombin: 250 (standard), 50 (1:5 dilution), and 25 (1:10 dilution) units/ml, and incubated for three different periods (5, 20, and 60 seconds). FGGSs were applied over two adjacently positioned porcine skins placed on two metallic plates. The adhesion strength was evaluated by measuring maximum tensile strength during pulling out the sliding plate at a constant rate of displacement. The maximum adhesion strength was greater for FGGS with 1:10 diluted thrombin solution than for FGGS prepared with higher concentrations (p $<0.05)$. Adhesion strength did not decay for 20 seconds after the mixture. Only four of 255 cases $(1.6 \%)$ required second reconstruction of sella floor due to the cerebrospinal fluid leakage. FGGS prepared with diluted thrombin solution can provide adequate adhesion strength for clinical use.
\end{abstract}

Key words: fibrin glue-soaked sponge, skull base, adhesion strength, transsphenoidal approach, reconstruction

\section{Introduction}

Cerebrospinal fluid (CSF) leaks are considered serious complications in neurosurgical procedures and efficient tissue sealing is an important preventative maneuver. Fibrin glue has been commercially available for more than 20 years and currently is being used in neurosurgical practice in many countries as a fixative of injured tissue, for hemostasis, and for

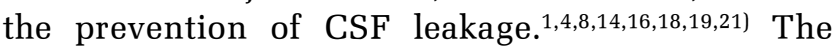
usefulness of collagen sponge, singly or in combination with fibrin sealants or artificial materials, has also been reported for dural repair. Collagen sponge with fibrin glue has yielded good results in the prevention of CSF leakage. ${ }^{9,11,13,14)}$ We have used fibrin glue-soaked gelatin sponge (FGGS) for tissue sealing in neurosurgical practice, especially for transsphenoidal surgery, for more than 10 years.

Received November 2, 2011; Accepted December 1,2011
However, too rapid clotting of fibrin glue occasionally prevents good fixation of the FGGS to the surrounding tissues. On such occasions, we have repeated the procedure using FGGS with diluted thrombin solution, resulting in good fixation. Based on these experiences, we have primarily employed this dilution technique to prepare FGGS for sellar reconstruction since April 2006, with good potential to prevent postoperative CSF leakage.

To confirm the adequacy of our clinical procedures, we performed experiments to evaluate the effect of thrombin dilution on the adhesion strength of FGGS, and retrospective assessment of sellar reconstruction using FGGS prepared with diluted thrombin solution (FGGS-DT).

\section{Materials and Methods}

Bolheal ${ }^{\circledR}$ fibrinogen $(80 \mathrm{mg} / \mathrm{ml}+$ blood coagulation factor XIII 75 units/ml + bovine aprotinin 1000 units $/ \mathrm{ml}$ ) and thrombin solution (250 units $/ \mathrm{ml}+$ cal- 


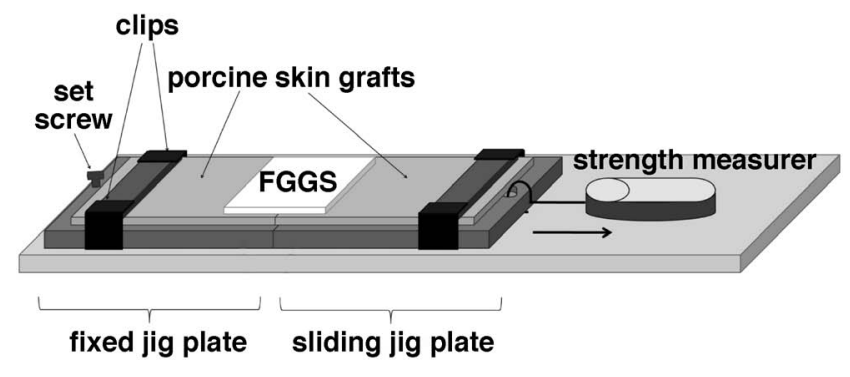

Fig. 1 Schematic illustration of the device used for measuring adhesion strength of fibrin glue-soaked gelatin sponge (FGGS) to the porcine skin graft. Two porcine skin grafts were placed adjacent, one on a fixed plate and the other on the sliding plate which was hooked to the traction speed measurer. Skin grafts were clipped on the slides. FGGS was then placed onto the skin graft junction and a sinker (123 g) was placed for compression for 3 minutes. Traction was applied at $50 \mathrm{~mm} / \mathrm{min}$ by a speed controller. Then the drawing strength $(\mathrm{J})$ was evaluated by a strength measurer attached to the speed controller.

cium chloride $40 \mu \mathrm{mol} / \mathrm{ml}$ ) were obtained from The Chemo-Sero-Therapeutic Research Institute, Kumamoto, Kumamoto. Absorbable gelatin compressed sponge (Gelfoam ${ }^{\circledR}$ ) was obtained from Pfizer, New York, New York, USA. One hundred eight pre-treated porcine skin grafts were stored at $-18^{\circ} \mathrm{C}$ after removal of fat to avoid variations in the adhesion strength. Just before the experiment, the skin grafts were unfrozen at room temperature, moisturized, and then wiped with gauze. Porcine skin grafts and measuring devices were prepared and operated according to standard test method for wound closure strength of tissue adhesives and sealants, F2458, 2005. ${ }^{2)}$

Two porcine skin grafts were placed on metallic jig plates (IDM Corporation, Koshi, Kumamoto) adjacent to one another and fixed on the plates with clips (Fig. 1). Three solutions with different concentrations of thrombin were prepared: 250 units $/ \mathrm{ml}$ (standard), 50 units $/ \mathrm{ml}$ (1:5 dilution, prepared by mixing $200 \mu \mathrm{l}$ of standard thrombin solution with $800 \mu \mathrm{l}$ of $0.9 \%$ physiological saline), and 25 units $/ \mathrm{ml}$ (1:10 dilution, prepared by mixing $100 \mu \mathrm{l}$ of standard thrombin solution with $900 \mu$ l of $0.9 \%$ physiological saline). The surface of a gelatin sponge piece was briefly dipped in fibrinogen solution and then dipped in one of the three thrombin solutions. For each thrombin concentration, the FGGS was incubated for 5, 20, or 60 seconds. The FGGS was then placed onto the skin graft junction and a sinker (123 g) was placed over the FGGS, to apply compression for 3 minutes. Traction was applied at $50 \mathrm{~mm} / \mathrm{min}$ using a speed controller (Model-2257; Aikoh En-

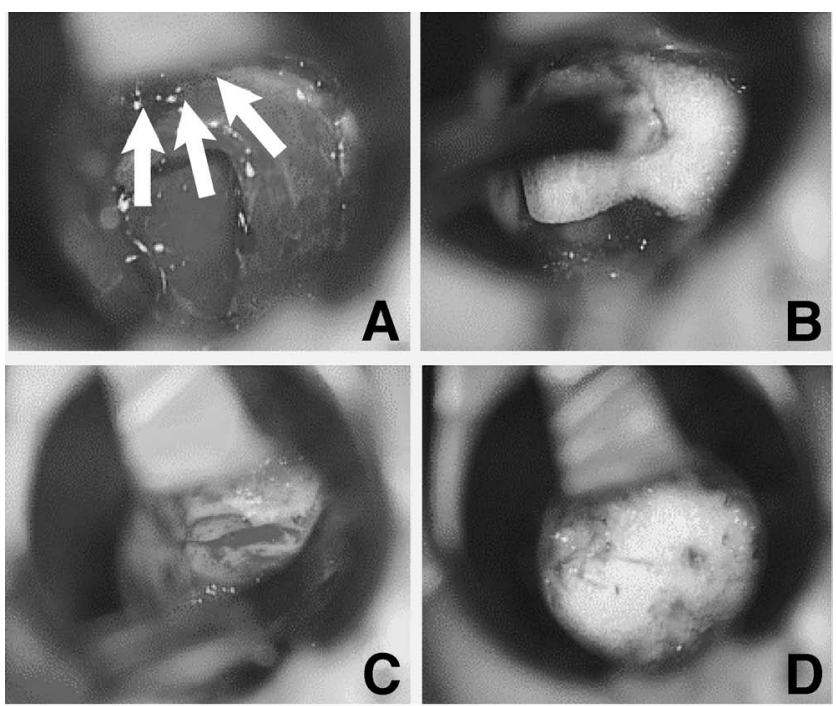

Fig. 2 Operating microscope views of the clinical application of fibrin glue-soaked gelatin sponge prepared with diluted thrombin solution (FGGS-DT) in a case of prolactinoma. A: Cerebrospinal fluid leakage was seen from the arachnoidal tear behind the tuberculum sellae (arrows) at the end of tumor removal. B: FGGS-DT was applied to the leakage point to primarily seal the defect. C: After packing of intrasellar dead space with the FGGS-DT, the sellar floor was reconstructed with a vomer splint. D: Reconstructed sellar floor was covered by FGGS-DT.

gineering Co., Ltd., Higashiosaka, Osaka), and the drawing strength in joules (J) was evaluated by a strength measurer (Model-9500; Aikoh Engineering Co., Ltd.) attached to the controller. The maximum drawing strength, always measured just before peeling of the FGGS away from the porcine skin graft, was considered to be the adhesion strength of FGGS. This procedure was repeated six times for each concentration and for each incubation time. Data on adhesion strength were collected, and means and standard deviation were calculated. Statistical differences between the adhesion strength, of different groups were determined by Tukey's multiple comparison tests at the $95 \%$ confidence level.

FGGS-DT was used for reconstruction of the sellar floor in 255 patients who underwent transsphenoidal surgery for pituitary lesions from April 2006 to September 2011. The lesions included 195 pituitary adenomas, 22 Rathke's cleft cysts, 10 craniopharyngiomas, 8 chordomas, 3 meningiomas, 3 germinomas, and 14 miscellaneous pathologies. Intraoperative CSF leakage was observed in 27 cases. After aspirating the CSF around the defect of the arachnoid membrane, the leakage point was primarily sealed with FGGS-DT (1:5 or 1:10) (Fig. 2). 
Then the dead space in the sella turcica was also filled with FGGS-DT. The sellar floor was reconstructed with a vomer splint. Two to three pieces of FGGS-DT were applied to cover the sellar floor. For wide defects of arachnoid membrane, not uncommon in transsphenoidal surgery of craniopharyngioma or meningioma, two to three pieces of FGGS-DT were applied for primary sealing of the defects, then adipose tissue was inserted under the FGGS-DT layer to secure the fixation. The sellar floor was reconstructed in the same manner. Spinal drainage of CSF was continued for 3 days in these cases. In cases without intraoperative CSF leakage, the dead space was filled with FGGS-DT, with the same procedure.

\section{Results}

The mean adhesion strength of the FGGS-DT prepared with 1:10 diluted thrombin solution was greater than those of FGGS-DT prepared with other solutions for all incubation times (Table 1). Analysis of variance and post-hoc Tukey's multiple comparison tests revealed no significant differences in the adhesion strengths between the three different incubation time groups when the standard thrombin was used. Maximum adhesion strength was observed for FGGS-DT was incubated for 5 seconds using 1:5 and 1:10 dilutions, but the difference from those incubated for 20 seconds was not statistically significant.

FGGS-DT was applied in 255 cases for the reconstruction of sellar floor with/without sealing of tear of arachnoid membrane at the end of transsphenoidal surgery. Autologous adipose tissue was also used in 19 cases. Postoperative CSF rhinorrhea needing second reconstruction of sellar floor ensued in only 4 cases (1.6\%) including a case of craniopharyngioma which needed extensive subarachnoid manipulation. No autologous adverse effects of FGGS were encountered.

Table 1 Adhesion strength of fibrin glue-soaked gelatin sponge to porcine skin graft

\begin{tabular}{|c|c|c|c|}
\hline \multirow{2}{*}{ Dilution } & \multicolumn{3}{|c|}{ Incubation time (sec) } \\
\hline & 5 & 20 & 60 \\
\hline $1: 1$ & $0.54 \pm 0.15$ & $0.55 \pm 0.20$ & $0.47 \pm 0.10$ \\
\hline $1: 5$ & $1.17 \pm 0.30^{*}$ & $0.96 \pm 0.21^{*}$ & $0.66 \pm 0.12^{* *}$ \\
\hline $1: 10$ & $1.34 \pm 0.13^{*}$ & $1.19 \pm 0.23^{*}$ & $0.95 \pm 0.27^{*}, * *$ \\
\hline
\end{tabular}

Values are mean \pm standard deviation in $\mathrm{J} .{ }^{*} \mathrm{p}<0.05$ compared with 1:1 dilution in the same incubation time group; ${ }^{* *} \mathrm{p}<0.05$ compared with $5 \mathrm{sec}$ using the same dilution.

\section{Discussion}

Our experimental study showed that 1:10 dilution of commercially available thrombin solution provides the greatest adhesion strength for FGGS-DT compared with higher concentration solutions. We posit that slow conjugation time with thinner thrombin gives enough time for the fibrinogen-thrombin mixture to spread onto the irregular surface of tissue before hardening, which provides stronger attachment of FGGS to the tissue. In addition, studies in tissue engineering have reported that increased thrombin concentration modifies the microfibril structure of the fibrin gels, by decreasing the fiber bundling size and so decreasing the porosity of the gel, which may lead to reduced adhesion strength. ${ }^{3,12,15)}$ Maximum adhesion strength of autologous fibrin glue was reported with thrombin concentration of 50 units $/ \mathrm{ml}$, and a significant decrease with thrombin concentrations over 200 units $/ \mathrm{ml}$, suggesting inhibition of fibrin association as thrombin increases. ${ }^{20)}$ Our studies showed that maximum strength was acquired using 25 units $/ \mathrm{ml}$ thrombin concentration, a slightly lower concentration. The use of gelatin sponge as a vehicle for the fibrin glue in our study may explain this discordance.

In the clinical setting, more than 5 seconds is sometimes required from soaking of gelatin sponge with fibrinogen then with thrombin to the final positioning of the FGGS on the defect, because shifting of the FGGS on the defect is usually required to achieve adequate sealing, and even repositioning is occasionally needed. This study shows adhesion strength was not significantly different between the incubation time of 5 seconds and 20 seconds, but decayed in 60 seconds. Therefore, the neurosurgeon has at least 20 seconds lag-time from the start of conjugation of fibrinogen and thrombin on the gelatin sponge until final positioning on the defect with maximum adhesion strength provided by the 1:10 dilution of thrombin.

The rate of the postoperative CSF rhinorrhea needing second reconstruction in our 255 consecutive cases of transsphenoidal surgery (1.6\%) appears lower than those of the preceding reports, $1.5-10 \%,,^{5-7,9,10,14,17)}$ and suggests the usefulness of FGGS with diluted thrombin solution in neurosurgical practice. However, the rate may be influenced by the radicality of the surgery for suprasellar lesions. Therefore, a prospective comparative clinical trial between standard and diluted thrombin solution is required, followed by a pathological study to identify the factors contributing to adhesion strength. 


\section{Acknowledgment}

This work was partly aided by a research grant, Research on Hypothalamo-Pituitary Dysfunction, from the Ministry of Health, Labour and Welfare of Japan (to K.A.). We thank to Mr. Yoshitaka Takegawa for his valuable technical advices and supports.

\section{Conflicts of Interest Disclosure}

The authors have no personal financial or institutional interest in any of the drugs, materials, or devices in the article. All authors who are members of The Japan Neurosurgical Society (JNS) have registered online Self-reported COI Disclosure Statement Forms through the website for JNS members.

\section{References}

1) Albala DM, Lawson JH: Recent clinical and investigational applications of fibrin sealant in selected surgical specialties. J Am Coll Surg 202: 685-697, 2006

2) American Society for Testing and Materials (ASTM): ASTM F2458-05, Standard test method for wound closure strength of tissue adhesives and sealants. West Conshohocken, PA, ASTM International, 2005. DOI: 10.1520/F2458-05. Available from: http://www. astm.org/DATABASE.CART/HISTORICAL/F245805.htm

3) Blombäck B, Carlsson K, Hessel B, Liljeborg A, Procyk R, Aslund N: Native fibrin gel networks observed by 3D microscopy, permeation and turbidity. Biochim Biophys Acta 997: 96-110, 1989

4) Cavallo LM, Messina A, Esposito F, De Divitidis O, Dal Fabbro M, De Divitiis E, Cappabianca P: Skull base reconstruction in the extended endoscopic transsphenoidal approach for suprasellar lesions. J Neurosurg 107: 713-720, 2007

5) Cho JM, Ahn JY, Chang JH, Kim SH: Prevention of cerebrospinal fluid rhinorrhea after transsphenoidal surgery by collagen fleece coated with fibrin sealant without autologous tissue graft or postoperative lumbar drainage. Neurosurgery 68(1 Suppl Operative): 130-137, 2011

6) Ciric I, Ragin A, Baumgartner C, Pierce D: Complications of transsphenoidal surgery: results of a national survey, review of the literature, and personal experience. Neurosurgery 40: 225-236, 1997

7) D'Haens J, Van Rompaey K, Stadnik T, Haentjens P, Poppe K, Velkeniers B: Fully endoscopic transsphenoidal surgery for functioning pituitary adenomas: a retrospective comparison with traditional transsphenoidal microsurgery in the same institution. Surg Neurol 72: 336-340, 2009

8) Dunn CJ, Goa KL: Fibrin sealant: a review of its use in surgery and endoscopy. Drugs 58: 863-886, 1999

9) Esposito F, Dusick JR, Fatemi N, Kelly DF: Graded repair of cranial base defects and cerebrospinal fluid leaks in transsphenoidal surgery. Neurosurgery 60: 295-303, 2007

10) Han ZL, He DS, Mao ZG, Wang HJ: Cerebrospinal fluid rhinorrhea following trans-sphenoidal pituitary macroadenoma surgery: experience from 592 patients. Clin Neurol Neurosurg 110: 570-579, 2008

11) Kelly DF, Oskouian RJ, Fineman I: Collagen sponge repair of small cerebrospinal fluid leaks obviates tissue grafts and cerebrospinal fluid diversion after pituitary surgery. Neurosurgery 49: 885-889, 2001

12) Kubota K, Kogure H, Masuda Y, Toyama Y, Kita R, Takahashi A, Kaibara M: Gelation dynamics and gel structure of fibrinogen. Colloids Surf B Biointerfaces 38: 103-109, 2004

13) Nistor RF, Chiari FM, Maier H, Hehl K: The fixed combination of collagen with components of fibrin adhesive-a new hemostypic agent in skull base procedures. Skull Base Surg 7: 23-30, 1997

14) Rabadán AT, Hernández D, Ruggeri CS: Pituitary tumors: our experience in the prevention of postoperative cerebrospinal fluid leaks after transsphenoidal surgery. J Neurooncol 93: 127-131, 2009

15) Rowe SL, Lee S, Stegemann JP: Influence of thrombin concentration on the mechanical and morphological properties of cell-seeded fibrin hydrogels. Acta Biomater 3: 59-67, 2007

16) Shaffrey CI, Spotnitz WD, Shaffrey ME, Jane JA: Neurosurgical applications of fibrin glue: augmentation of dural closure in 134 patients. Neurosurgery 26: 207-210, 1990

17) Shiley SG, Limonadi F, Delashaw JB, Barnwell SL, Andersen PE, Hwang PH, Wax MK: Incidence, etiology, and management of cerebrospinal fluid leaks following trans-sphenoidal surgery. Laryngoscope 113: 1283-1288, 2003

18) Spotnitz WD: Commercial fibrin sealants in surgical care. Am J Surg 182(2 Suppl): 8S-14S, 2001

19) Van Velthoven V, Clarici G, Auer LM: Fibrin tissue adhesive sealant for the prevention of CSF leakage following transsphenoidal microsurgery. Acta Neurochir (Wien) 109: 26-29, 1991

20) Yoshida H, Hirozane K, Kamiya A: Adhesive strength of autologous fibrin glue. Biol Pharm Bull 23: 313-317, 2000

21) Yoshimoto T, Sawamura Y, Houkin K, Abe H: Effectiveness of fibrin glue for preventing postoperative extradural fluid leakage. Neurol Med Chir (Tokyo) 37: 886-890, 1997

Address reprint requests to: Kazunori Arita, MD, Professor and Chairman, Department of Neurosurgery, Graduate School of Medical and Dental Sciences, Kagoshima University, 8-35-1 Sakuragaoka, Kagoshima 890-8520, Japan.

e-mail: karita@m2.kufm.kagoshima-u.ac.jp 